Check for updates

Cite this: RSC Adv., 2018, 8, 13048

Received 31st January 2018

Accepted 30th March 2018

DOI: $10.1039 / c 8 r a 00982 a$

rsc.li/rsc-advances

\section{Fast and simple transesterification of epoxidized soybean oil to prepare epoxy methyl esters at room temperature}

\author{
Wei Liu, (D) * Feifei Duan and Yanlan Bi \\ Epoxidized soybean oil methyl esters were prepared via transesterification of epoxidized soybean oil (ESBO) \\ with methanol catalyzed by cheap and stable sodium hydroxide $(\mathrm{NaOH})$. The transesterification could be \\ completed in only $5 \mathrm{~min}$ at room temperature $\left(25^{\circ} \mathrm{C}\right)$ without loss of the epoxide function and the \\ transesterification rate was promoted significantly while the utilization of $5 \%$ acetone as co-solvent. The \\ afforded products epoxidized methyl esters represent a renewable substrate that is readily converted \\ into surfactants, fuel additives and other valuable industrial products.
}

\section{Introduction}

Biobased products, some of the most important renewable materials, are widely used in fuels, polymers, coatings, and other specialty products. Among those, vegetable oils serve as one of the most versatile renewable substrates in chemical and related industries, which can be converted into various valuable products due to their abundant availability. ${ }^{1}$

Soybean oil (SBO) is a kind of particularly useful substrates for the production of biobased products because of the number of unsaturated bonds contained in the component fatty acids (IV $\left.=124-139 \mathrm{~g} \mathrm{I}_{2} / 100 \mathrm{~g}\right)$ and the low cost (\$1000-1200/ton) compared with other plant oils resources (rapeseed, sunflower, etc). ${ }^{2,3}$ The epoxidized soybean oil (ESBO) is one of the most useful chemical intermediates for the preparation of derivatives, such as lubricants, plasticizers, adhesives and rubber-like materials. ${ }^{4-9}$ Based on the classical chemical epoxidation method, ${ }^{10}$ the epoxidation of vegetable oils (e.g. soybean oil) is performed on an industrial scale and the epoxidized soybean oil (ESBO) can be provided in million tons per year. With the development of oleochemical industry and demand for renewable materials, the interest in utilizing the vegetable oil esters for new products is growing. ${ }^{11-13}$ However, the supply of epoxidized methyl esters which can be served as the chemical intermediate for new biobased products is currently limited compared to the commercially available epoxidized vegetable oils.

Using soybean oil (SBO) as the starting material, the epoxidized soybean oil methyl esters (ESBOME) could be obtained through two main processes based on an industrial scalable technology (Scheme 1). In process (A), soybean oil (SBO) took

College of Food Science and Technology, Henan University of Technology, Lianhua Street 100, Zhengzhou 450001, P. R. China.E-mail: liuwei307@hotmail.com; Fax: +86-371-67758022; Tel: +86-371-67758022 place transesterification with methanol to produce soybean oil methyl esters (SBOME) in the presence of strong bases (e.g. $\mathrm{NaOH}, \mathrm{KOH}, \mathrm{CH}_{3} \mathrm{ONa}$ ) as catalyst at $60-70{ }^{\circ} \mathrm{C},{ }^{14}$ and then SBOME undergo epoxidation catalyzed by strong acids (e.g. $\mathrm{H}_{2} \mathrm{SO}_{4}$ ) at $40-60{ }^{\circ} \mathrm{C}$ in the presence of $\mathrm{H}_{2} \mathrm{O}_{2} \cdot{ }^{15}$ The whole process (A) was required heating at each steps. As for process (B), soybean oil (SBO) firstly took place epoxidation to produce epoxidized soybean oil (ESBO), ${ }^{\mathbf{1 6}}$ which then underwent transesterification with methanol to produce the epoxidized soybean oil methyl esters (ESBOME). Direct transformation of epoxidized soybean oil to ESBOME is highly attractive due to the large amount of epoxidized soybean oil produced in oleochemical industry each year. Holser reported that sodium methoxide $\left(\mathrm{CH}_{3} \mathrm{ONa}\right)$ could serve as an efficient catalyst for transesterification of epoxidized soybean oil (ESBO) with methanol at $50{ }^{\circ} \mathrm{C}^{17}$ Considering the moisture sensitivity of $\mathrm{CH}_{3} \mathrm{ONa}$ and the possible dangers in large scale process, ${ }^{\mathbf{1 8 - 2 0}}$ a sustainable method is highly desirable for fast and simple transesterification of epoxidized vegetable oil (e.g. soybean oil) to prepare epoxy methyl esters products in mild conditions, such as stable and cheap bases and room temperature operations.

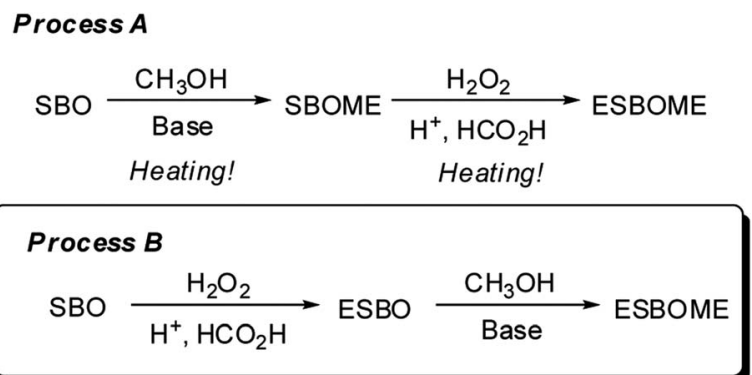

Scheme 1 The comparison of two processes for preparation of ESBOME. 
Oil phases and $\mathrm{CH}_{3} \mathrm{OH}$ are insoluble at room temperature in the transesterification process, therefore, the efforts have been focused on improving the solubility without increasing the reaction temperature recently. Several organic solvents like acetone, diethylether or tetrahydrofuran have been proved to promote the transesterification reaction effectively as co-solvent at even room temperature. ${ }^{21-24}$ Inspired by the co-solvent method for transesterification to produce biodiesel, we started to investigate the preparation of epoxidized methyl esters by transesterification of epoxidized vegetable oils at room temperature $\left(25^{\circ} \mathrm{C}\right)$ (Scheme 2$)$, in which the epoxy group could be well tolerated. This novel and sustainable protocol could make a large supply of epoxidized methyl esters become available and stimulate the development of new biobased products.

\section{Materials and methods}

\section{Materials}

Epoxidized soybean oil was purchased from Aladdin Chemical Reagent (Shanghai, China). $\mathrm{CH}_{3} \mathrm{ONa}$ (>99\%) was purchased from Aladdin Chemical Reagent (Shanghai, China). $\mathrm{NaOH}$, $\mathrm{KOH}, \mathrm{Na}_{2} \mathrm{CO}_{3}$, methanol, acetone, ethyl acetate, tetrahydrofuran (THF), diethylether and $n$-hexane were analytical reagent grade and purchased from Kermel Chemical Reagent (Tianjin, China). Monoglyceride, diglyceride standards were purchased from Sigma-Aldrich Co. (St. Louis, MO). Methyl heptadecanoate standard was purchased from Sigma-Aldrich Co. (St. Louis, MO). Triglyceride (soybean oil) were purchased from a local supermarket (Zhengzhou, China). Epoxidized fatty acid methyl esters standards were prepared in our lab through epoxidation of corresponding fatty acid methyl esters.

\section{Transesterification}

Transesterification reactions were performed in $50 \mathrm{~mL}$ roundbottom flask. Epoxidized soybean oil (10.0 g) and a certain

\section{Previous works}

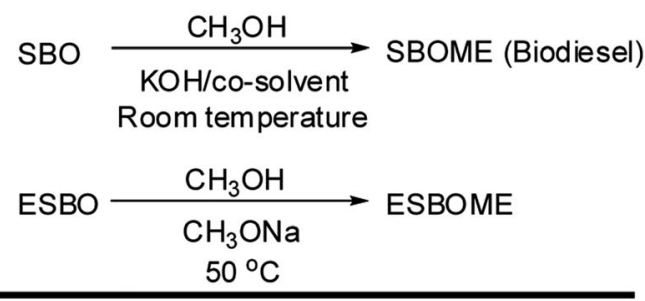

This work

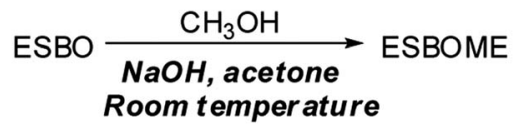

Cheap and stable base: $\mathbf{N a O H}$
Mild temperature: $25{ }^{\circ} \mathrm{C}$
Fast reaction: $\mathbf{5}$ min
Excellent yield: $\mathbf{9 9 . 7 \%}$

Scheme 2 The comparison of previous works for transesterification. amount of co-solvent were added to the flask. A solution of the established base concentration in methanol was prepared and added to the flask. Then the mixture was magnetically stirred at room temperature $\left(25^{\circ} \mathrm{C}\right)$ for $1 \mathrm{~h}$. After the reaction completion, the product was washed with deionizer water to remove the remaining base catalyst. And the remaining water was dried by anhydrous sodium sulfate $\left(\mathrm{Na}_{2} \mathrm{SO}_{4}\right)$. Finally, the product was dried under reduced pressure for $1 \mathrm{~h}$.

\section{Oxirane oxygen titrations}

Epoxy oxygen group content (EOC) of the products was determined by the titration method with hydrobromic acid solution in acetic acid using AOCS standard test method Cd 9-57 (AOCS, 1998).

\section{Gas chromatography analysis}

The products were analyzed using an Agilent 7890 GC equipped with a DB-1HT column $(30 \mathrm{~m} \times 0.25 \mathrm{~mm} \times 0.1 \mu \mathrm{m}, \mathrm{J} \& \mathrm{~W}$ Scientific, Folsom, CA). Nitrogen was used as the carrier gas with flowing rate of $5 \mathrm{~mL} \mathrm{~min}^{-1}$. The oven was programmed from an initial temperature of $50-180{ }^{\circ} \mathrm{C}$ at $15{ }^{\circ} \mathrm{C} \mathrm{min}^{-1}$, increased to $230{ }^{\circ} \mathrm{C}$ at $7{ }^{\circ} \mathrm{C} \min ^{-1}$, and then to $380{ }^{\circ} \mathrm{C}$ at $30{ }^{\circ} \mathrm{C} \mathrm{min}{ }^{-1}$ with a $15 \mathrm{~min}$ hold for a total run time of $35 \mathrm{~min}$. Detection of eluents was made by FID and identified by retention times compared to known standards. Fatty acid esters, monoglyceride, diglyceride, and triglyceride standards were used. Internal standard method was used with methyl heptadecanoate as standard.

\section{Statistical analysis}

All experiments were performed in triplicate. The statistical significance of the ESBOME yield was analyzed by a significance testing of one-factor. Statistical significance was considered at $p$ $<0.05$.

\section{Results and discussions}

\section{Effect of catalyst}

As known, base plays a key role in the transesterification reactions. Thus, the effect of catalyst on epoxidized soybean oil methyl esters (ESBOME) production was evaluated by different commonly used alkaline bases $\left(\mathrm{NaOH}, \mathrm{KOH}, \mathrm{CH}_{3} \mathrm{ONa}\right.$ and $\mathrm{Na}_{2} \mathrm{CO}_{3}$ ) with $0.5 \%$ ( $\mathrm{wt} \%$ of oil) catalyst loading at room temperature $\left(25^{\circ} \mathrm{C}\right)$. Meanwhile, $20 \%$ (wt $\%$ of oil) acetone was added as co-solvent to increase the solubility of oil phases and $\mathrm{CH}_{3} \mathrm{OH}$ and reduce the proportion of $\mathrm{CH}_{3} \mathrm{OH},{ }^{23,24}$ which was used as both reactant and solvent in transesterification reaction between oil and $\mathrm{CH}_{3} \mathrm{OH}$. Considering the sequence of reactant addition might influence the reaction rate, the solid base (e.g. $\mathrm{NaOH}$ ) dissolved in methanol and the obtained mixtures (basemethanol) were added together into the reaction, which make the actual concentrations of different bases were the same in the reaction system. As shown in Fig. 1, $\mathrm{KOH}$ and $\mathrm{NaOH}$ showed higher catalytic efficiency than the same amount of $\mathrm{CH}_{3} \mathrm{ONa}$ at room temperature, which might take place the side reaction with acetone. The methyl ester yield of ESBOME using $\mathrm{KOH}$ or 


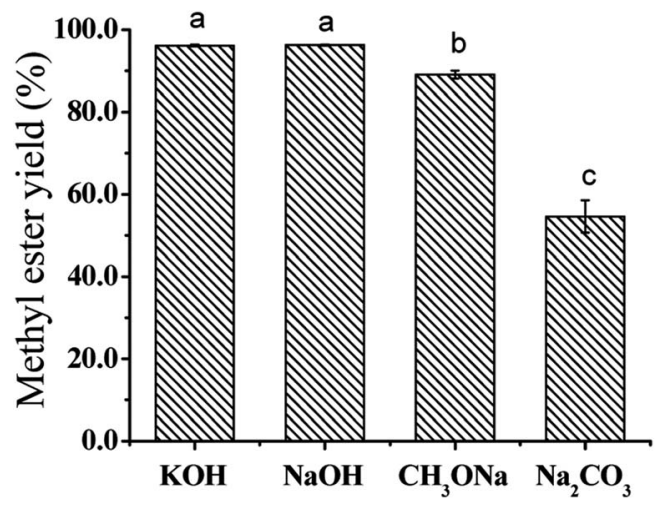

Fig. 1 Effect of different catalysts on the ESBOME production (reaction conditions: $25{ }^{\circ} \mathrm{C}, 20 \%$ (wt\% of oil) acetone as solvent, $6: 1$ of methanol/oil molar ratio, $500 \mathrm{rpm}, 1 \mathrm{~h}$ ). Bars with the same letter are not significantly different.

$\mathrm{NaOH}$ as catalyst were $96.2 \%$ and $96.3 \%$, respectively, which indicated that $\mathrm{KOH}$ and $\mathrm{NaOH}$ exhibited the similar catalytic activity towards the transersterification process. Less strong base such as $\mathrm{Na}_{2} \mathrm{CO}_{3}$ was also examined in this mild transersterification process giving much lower methyl ester yield of ESBOME (54.6\%). Considering the reaction activity and the lower cost in the scalable production for biobased products, $\mathrm{NaOH}$ was chosen as the optimal catalyst at room temperature and applied in the following experiments.

\section{Effect of catalyst loading}

In order to investigate the effect of catalyst loading on ESBOME production, a series of experiments were conducted in the presence of $\mathrm{NaOH}$ catalyst at room temperature in the range of $0.10-1.30 \%$ (wt\% of oil) (Fig. 2). In general, more $\mathrm{NaOH}$ base used in the transesterification process led to higher conversion of ESBO, which indicated that the transersterification rate was enhanced obviously with the increase of catalyst loading. And the transesterification process using only $0.1 \% \mathrm{NaOH}$ catalyst led to $86.0 \%$ methyl ester yield of ESBOME. When the amount

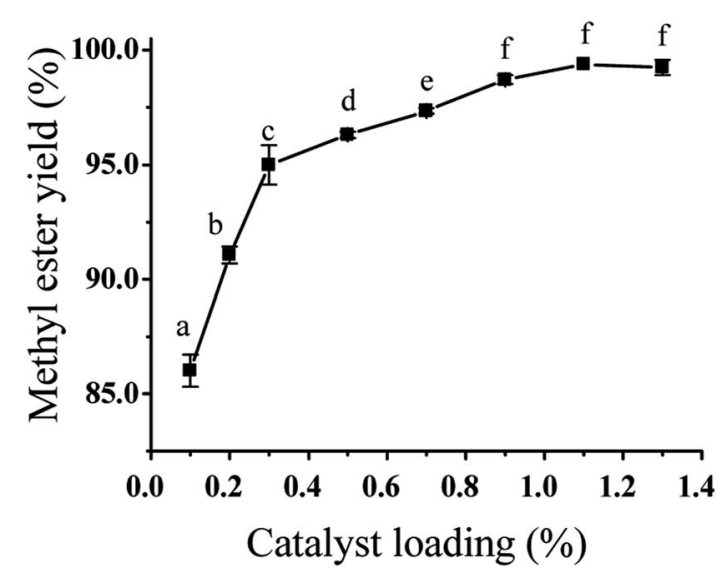

Fig. 2 Effect of catalyst loading on the ESBOME production (reaction conditions: $25{ }^{\circ} \mathrm{C}, 20 \%$ (wt\% of oil) acetone as solvent, $6: 1$ of methanol/oil molar ratio, $500 \mathrm{rpm}, 1 \mathrm{~h}$ ). Bars with the same letter are not significantly different. of catalyst $\mathrm{NaOH}$ was increased from $0.2 \%$ to $1.1 \%$, the yield of ESBOME was significantly improved from $91.1 \%$ to $99.4 \%$. However, further increasing the amount of $\mathrm{NaOH}(1.3 \%)$ could not increase the yield of ESBOME. Therefore, the optimum ESBOME production was achieved in methyl ester yield of $99.4 \%$ when $1.1 \%$ of $\mathrm{NaOH}$ was employed as the transersterification catalyst.

\section{Effect of solvent type}

Transesterification reaction between oil and methanol is initially heterogeneous due to the poor solubility of the oil in methanol. ${ }^{21,22}$ Therefore, mass transfer between the two phases strongly affects the transesterification reaction rate. The using of co-solvent in the transesterification reaction was an efficient approach to solve this problem and decrease the amount of methanol. ${ }^{25}$ The effect of a variety of solvents such as acetone, ethyl acetate, THF and diethylether as co-solvent were tested. As shown in Fig. 3, acetone and diethylether showed the highest yields of ESBOME, which were all higher than 99\%. Ethyl acetate and THF showed lower efficiency than acetone and diethylether. Considering diethylether as solvent is unsafe (the boiling point of diethylether is $34.6^{\circ} \mathrm{C}$ ) for scalable process and more expensive in cost, while acetone is less toxic and can be used in food and feed industries in scalability. Therefore, the following experiments were carried out using acetone as cosolvent.

\section{Effect of molar ratio of methanol/oil}

The molar ratio of methanol/epoxidized soybean oil strongly affected the transesterification reaction rate and conversion. Because the stoichiometric molar ratio of methanol/epoxidized soybean oil (ESBO) was $3: 1$ according to the transesterification reaction, excess amount of methanol was commonly used to ensure complete conversion of epoxidized soybean oil. Without extra co-solvent (e.g. acetone), large excess of methanol and enhanced temperature $\left(60-70{ }^{\circ} \mathrm{C}\right)$ were required in

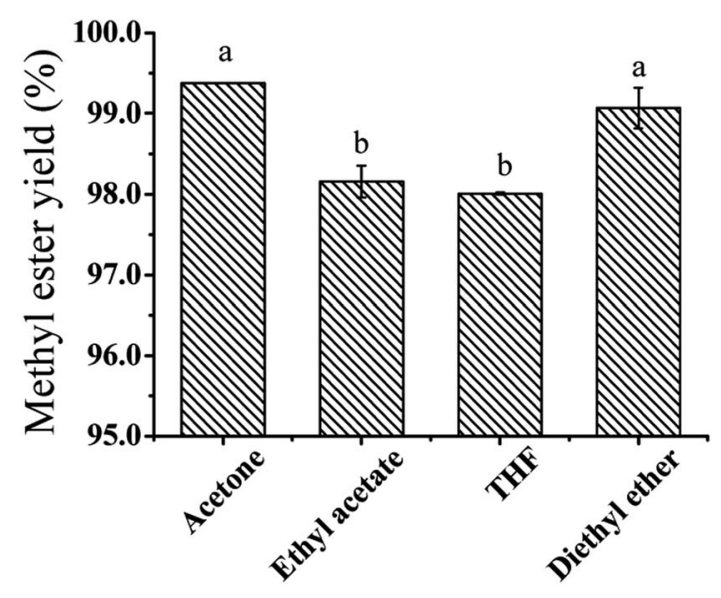

Fig. 3 Effect of different co-solvent on the ESBOME production (reaction conditions: $25^{\circ} \mathrm{C}, 20 \%$ solvent (wt\% of oil), $6: 1$ of methanol/ oil molar ratio, $1.1 \%$ (wt\% of oil) $\mathrm{NaOH}, 500 \mathrm{rpm}, 1 \mathrm{~h}$ ). Bars with the same letter are not significantly different. 
transesterification of vegetable oils to produce biodiesel. ${ }^{25}$ In this study, the molar ratio of methanol/ESBO ranging from $4: 1$ to $18: 1$ was optimized. As shown in Fig. 4, when the molar ratio of methanol/ESBO was increased from $4: 1$ to $14: 1$, the yield of ESBOME was increased slightly from $98.8 \%$ to $99.7 \%$. Continuing increasing the amount of methanol (18:1) could not further promote the yield of ESBOME. Therefore, the optimal molar ratio of methanol/ESBO was 14:1 and the methyl ester yield of ESBOME could reach to $99.7 \%$ under such mild reaction conditions.

\section{Effect of co-solvent amount}

In the transesterification process, using acetone as co-solvent, methanol and epoxidized soybean oil could better integrate and the reaction rate was increased. However, the amount of cosolvent could also affect the substrates concentration in the reaction system. Therefore, the amount of co-solvent (wt $\%$ of oil) was investigated in the range of $0-25 \%$. Fig. 5 showed the effect of co-solvent amount on the ESBOME production. Compared with none co-solvents, the yield of ESBOME was increased slightly (99.5\% vs. 99.7\%) after reaction for $1 \mathrm{~h}$ when $5 \%$ (wt\% of oil) acetone was added as co-solvent. Continuing increasing the amount of acetone (10-25\%), the yield of ESBOME exhibited no change (>99.5\%).

\section{Effect of reaction time}

Moreover, the whole reaction process of the transesterification between epoxidized soybean oil and methanol was monitored in the presence and absence of co-solvent (acetone, 5\%) (Fig. 6). Importantly, we found that the transesterification reaction between ESBO and methanol took place rapidly and complete conversion was detected only after stirring for $5 \mathrm{~min}$ at room temperature $\left(25{ }^{\circ} \mathrm{C}\right)$. Without extra co-solvent, the transesterification reaction between ESBO and methanol took place much slower than that with acetone as co-solvent and $30 \mathrm{~min}$ was required to finish the transesterification process. The starting material ESBO had high viscosity at room temperature.

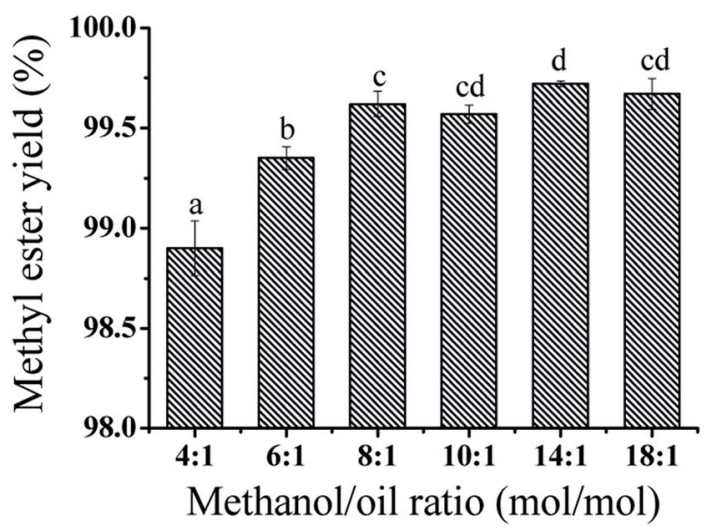

Fig. 4 Effect of methanol/oil molar ratio on the ESBOME production (reaction conditions: $25^{\circ} \mathrm{C}, 20 \%$ acetone (wt\% of oil), $1.1 \% \mathrm{NaOH}$ (wt\% of oil), $500 \mathrm{rpm}, 1 \mathrm{~h}$ ). Bars with the same letter are not significantly different

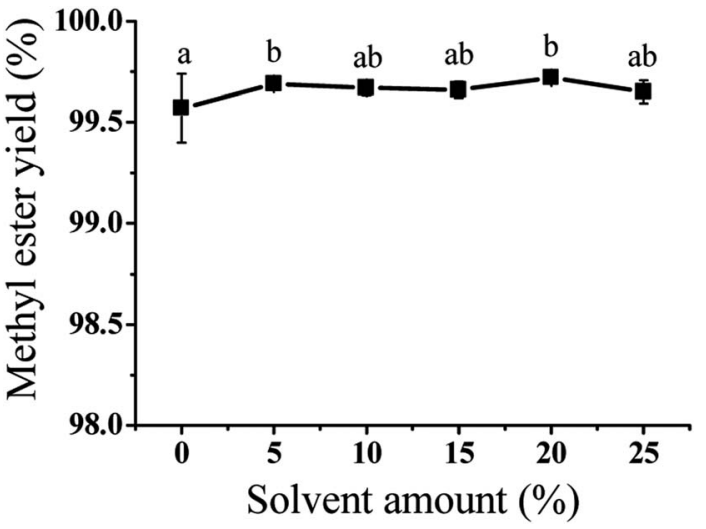

Fig. 5 Effect of co-solvent (acetone) amount on the ESBOME production (reaction conditions: $25^{\circ} \mathrm{C}, 1.1 \%$ (wt\% of oil) $\mathrm{NaOH}$, molar ratio of methanol/oil $14: 1,500 \mathrm{rpm}, 1 \mathrm{~h}$ ). Bars with the same letter are not significantly different.

Acetone as co-solvent could reduce the viscosity of ESBO, and increase the interaction between methanol and ESBO, so that the rate of transesterification was improved. Based on these observations, it was concluded that $5 \%$ acetone as co-solvent could efficiently promote the transesterification reaction in a very short time (5 min) even at such mild temperature $\left(25^{\circ} \mathrm{C}\right)$. Considering the rapid reaction rate observed in this transesterification, the activation energy of this reaction was also calculated. The result indicated that the activation energy was $31.29 \mathrm{~kJ} \mathrm{~mol}^{-1}$, which was relatively small and similar with the previous examples using $\mathrm{NaOH}$ as catalyst in transesterification vegetable oils with methanol. ${ }^{22,26}$ Thus, $5 \%$ acetone was chosen as co-solvent in the production of ESBOME through transesterification of ESBO with methanol.

This transesterification reaction occurs through three consecutive reactions. ${ }^{22}$ The first step is the reaction between one molecule of triglyceride (epoxidized soybean oil) and methanol to produce a diglyceride and one molecule of methyl ester (ESBOME). The obtained diglyceride reacts with methanol to form a monoglyceride and another molecule of ESBOME. In the final step, monoglyceride reacts with methanol to yield the

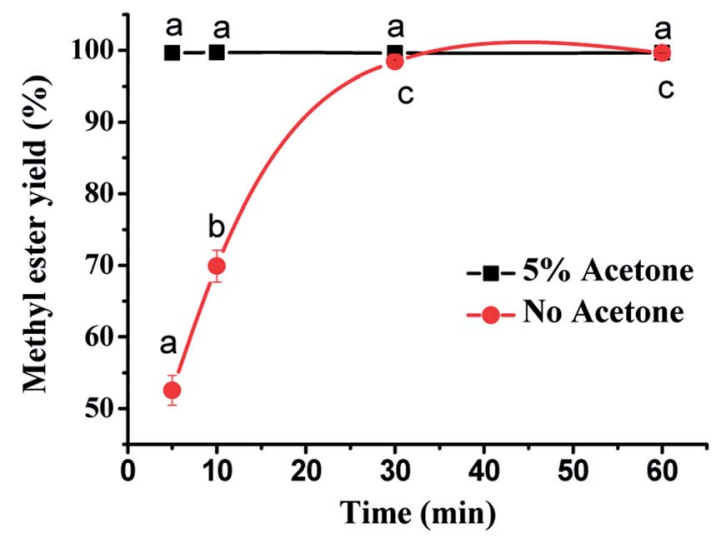

Fig. 6 Effect of co-solvent (acetone) on the reaction rate (reaction conditions: $25{ }^{\circ} \mathrm{C}, 1.1 \% \mathrm{NaOH}$ (wt\% of oil), molar ratio of methanol/oil $14: 1,500 \mathrm{rpm}$ ). Bars with the same letter are not significantly different. 
third molecule of ESBOME and one molecule of glycerol. Thus three molecules of ESBOME and one molecule of glycerol are formed by the completion of the transesterification reaction. Triglycerides are first converted to diglycerides, and because they are formed in the methanol phase, they have a greater chance of reacting there rather than moving back to the oil phase. Therefore, diglycerides and monoglycerides could not be observed after the completion of the transesterification reaction.

In addition, the transesterification reaction of soybean oil was tested under the same reaction conditions (using 5\% acetone as co-solvent). And the results showed that the transesterification reaction of soybean oil is slightly slower than that of epoxidized soybean oil. $95.1 \%$ yield of methyl esters was obtained after $5 \mathrm{~min}$. The above results suggested that the solubility of soybean oil in methanol affected the transesterification reaction indeed.

The changes of the oxirane oxygen values during transesterification of ESBO were also evaluated (Fig. 7). The oxirane oxygen values of the starting material ESBO was 6.2. During the transesterification reaction catalyzed by $\mathrm{NaOH}$ at room temperature, the oxirane oxygen values of the samples had nearly no change when oxirane oxygen value was determined at $5 \mathrm{~min}, 10 \mathrm{~min}, 30 \mathrm{~min}$ and $60 \mathrm{~min}$ respectively. Based on these observations, it was concluded that the transesterification was completed in $5 \mathrm{~min}$ at room temperature without loss of the epoxide function, which made this method fully tolerate unstable epoxide group. Recently, real-time FTIR has become one of the efficient and in situ tools to monitor organic transformations compared with conventional analysis tools such as GC, GC-MS and HPLC, ${ }^{27}$ which need pre-treatment before instruments analysis. Hence, real-time FTIR was used to monitor this transesterification progress at room temperature $\left(25{ }^{\circ} \mathrm{C}\right)$ (Fig. 8), which also indicated that the epoxide group $\left(845 \mathrm{~cm}^{-1}\right.$ ) had nearly no change during the whole transesterification reaction process.

Gas chromatography was used as an efficient tool to detect methyl esters, triglycerides (TG), intermediate transesterification products, monoglycerides (MG) and diglycerides

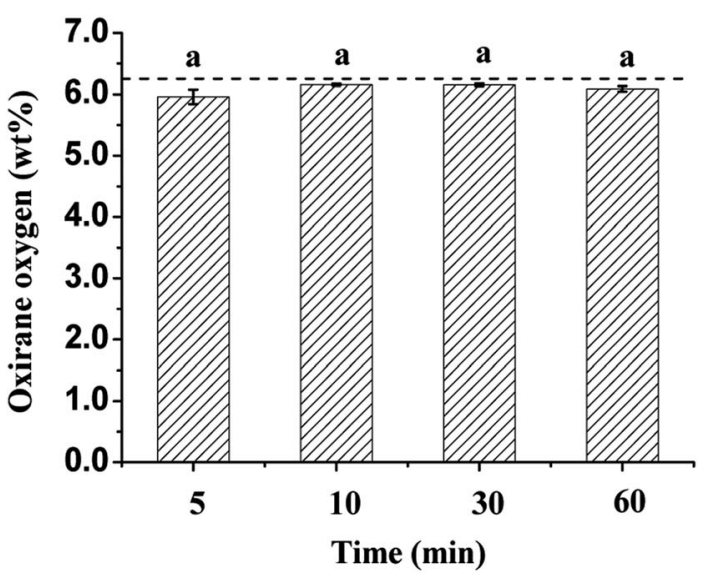

Fig. 7 Oxirane oxygen values changes during transesterification of ESBO. Bars with the same letter are not significantly different.

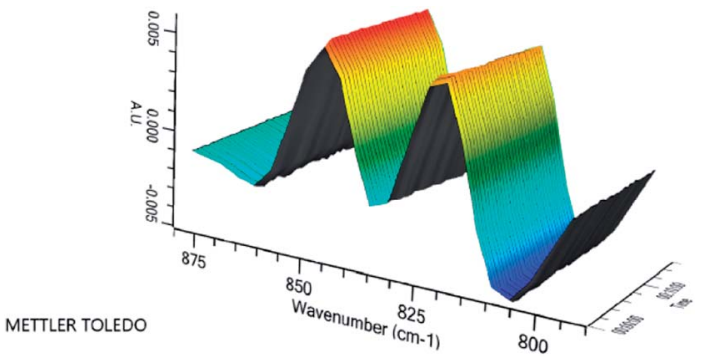

Fig. 8 The change of epoxide group $\left(845 \mathrm{~cm}^{-1}\right)$ during the transesterification progress monitored by real-time FT-IR.

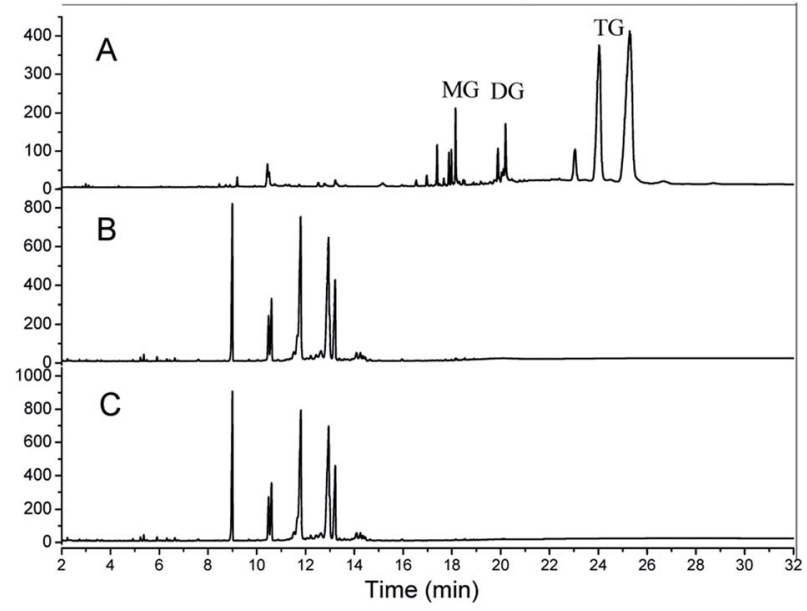

Fig. 9 Gas chromatograph of transesterification products: (A) monoglyceride (MG), diglyceride (DG), triglyceride (TG) standard compounds; (B) transesterification of ESBO after 5 min; (C) transesterification of ESBO after $60 \mathrm{~min}$.

(DG) in one batch analysis of the transesterification products. ${ }^{17}$ The transesterification products were showed in the Fig. 9A. The transesterified epoxidized soybean oil were analysized at $5 \mathrm{~min}$ (B) and $60 \mathrm{~min}$ (C) during the transesterification reaction, which suggested that the transesterification reaction proceeded rapidly. And the yield of ESBOME could reach to $99.7 \%$, nearly completed at the first $5 \mathrm{~min}$.

\section{Conclusions}

We have successfully developed a fast and simple method for transesterification of epoxidized soybean oil to prepare epoxy methyl esters at room temperature $\left(25^{\circ} \mathrm{C}\right)$. Epoxidized methyl esters were obtained in an excellent yield of $99.7 \%$ by the transesterification of epoxidized soybean oil (ESBO) with methanol catalyzed by $1.1 \%$ of cheap and stable sodium hydroxide $(\mathrm{NaOH})$. Importantly, this transesterification was completed within $5 \mathrm{~min}$ at room temperature without loss of the epoxide function. In addition, $5 \%$ acetone served as an efficient co-solvent to promote the transesterification reaction rate. This novel protocol provides an efficient and sustainable method towards the synthesis of epoxidized methyl esters. 


\section{Conflicts of interest}

There are no conflicts to declare.

\section{Acknowledgements}

The authors gratefully acknowledge the China Postdoctoral Science Foundation funded project (No. 2017M622364) and Basic Research Funds in Henan Universities of Henan University of Technology (No. 2015RCJH01).

\section{References}

1 U. Biermann, U. Bornscheuer, M. A. R. Meier, J. O. Metzger and H. J. Schäfer, Angew. Chem., Int. Ed., 2011, 50, 38543871.

2 M. Fan, P. Zhang and Q. Ma, Bioresour. Technol., 2012, 104, 447-450.

3 W. Shi, H. Li, R. Zhou, H. Zhang and Q. Du, Bioresour. Technol., 2016, 210, 43-48.

4 J. Dai, S. Ma, Y. Wu, L. Han, L. Zhang, J. Zhu and X. Liu, Green Chem., 2015, 17, 2383-2392.

5 A. Li and K. Li, ACS Sustainable Chem. Eng., 2014, 2, 20902096.

6 C. Li, J. Sung and X. S. Sun, ACS Sustainable Chem. Eng., 2016, 4, 1231-1239.

7 C. Liu, Y. Dai, Y. Hu, Q. Shang, G. Feng, J. Zhou and Y. Zhou, ACS Sustainable Chem. Eng., 2016, 4, 4208-4216.

8 V. M. Mello, G. B. C. Martins, M. d. A. Montenegro and P. A. Z. Suarez, Ind. Crops Prod., 2015, 66, 255-261.

9 Y. Xu, L. Yuan, Z. Wang, P. A. Wilbon, C. Wang, F. Chu and C. Tang, Green Chem., 2016, 18, 4974-4981.

$10 \mathrm{M}$. W. Formo, in Bailey's industrial oil and fat products, ed. D. Swern, Wiley, New York, 4th edn, 1982, pp. 366-371.
11 W. Huang, C. Park and J. Kim, Bioresour. Technol., 2017, 226, 94-98.

12 M. A. Kalam, M. M. Rashed, H. K. Imdadul and H. H. Masjuki, Ind. Crops Prod., 2016, 87, 333-339.

13 N. Tenhumberg, H. Buettner, B. Schaeffner, D. Kruse, M. Blumenstein and T. Werner, Green Chem., 2016, 18, 3775-3788.

14 E. Modiba, P. Osifo and H. Rutto, Ind. Crops Prod., 2014, 59, 50-54.

15 A. Campanella, C. Fontanini and M. A. Baltanás, Chem. Eng. J., 2008, 144, 466-475.

16 S. Dinda, A. V. Patwardhan, V. V. Goud and N. C. Pradhan, Bioresour. Technol., 2008, 99, 3737-3744.

17 R. A. Holser, Ind. Crop Prod., 2008, 27, 130-132.

18 Q. Kwok, B. Acheson, R. Turcotte, A. Janès and G. Marlair, J. Hazard. Mater., 2013, 250, 484-490.

19 T. Kai, G. Mak, S. Wada, T. Nakazato, H. Takanashi and Y. Uemura, Bioresour. Technol., 2014, 163, 360-363.

20 Y. Lin, K. Hsu and J. Lin, Fuel, 2014, 115, 306-311.

21 L. T. Thanh, K. Okitsu, Y. Sadanaga, N. Takenaka and Y. Maeda, Fuel, 2013, 103, 742-748.

22 J. Encinar, A. Pardal and N. Sanchez, Fuel, 2016, 166, 51-58. 23 D. Phuong, T. Hoa, V. Boi, N. Lan, I. Kyoshi, T. Norimichi and M. Yasuaki, Bioresour. Technol., 2014, 173, 309-316.

24 Y. Zhang, Y. Li, X. Zhang and T. Tan, Bioresour. Technol., 2015, 196, 712-715.

25 A. Abbaszaadeh, B. Ghobadian, M. R. Omidkhah and G. Najafi, Energy Convers. Manage., 2012, 63, 138-148.

26 L. Wu, T. Wei, Z. Lin, Y. Zou, Z. Tong and J. Sun, Fuel, 2016, 182, 920-927.

27 N. E. Leadbeater, Chem. Commun., 2010, 46, 6693-6695. 